\title{
Individual Trust Development in Business Virtual Teams: An Experimental Study
}

\author{
Xusen Cheng \\ University of International \\ Business and Economics, \\ Beijing,China \\ xusen.cheng@gmail.com
}

\author{
Tingting Hou \\ University of International \\ Business and Economics, \\ Beijing,China \\ htt94@foxmail.com
}

\author{
Shixuan Fu \\ University of International \\ Business and Economics, \\ Beijing,China \\ fsx8888@163.com
}

\author{
Jianshan Sun \\ Hefei University of \\ Technology, \\ Hefei, China \\ sunjs9413@hfut.edu.cn
}

\begin{abstract}
This paper presents a longitudinal study of individual trust development in virtual collaboration in China. We review the concept of trust, trust factors, and examine the development of individual trust and explore why individual trust changes over time. Risk, benefit, and interest are main trust factors that influence the development of individual trust. Survey data were collected at three points to observe the development of individual trust. In addition, we took semi-structured interviews to verify the development of individual trust and explore why individual trust changes in business virtual teams. We found that individual trust was improved over time and three main individual trust factors changed in different patterns. Moreover, conflict of option, interpersonal communication, information sharing and team working were found to be related with individual trust by the relationship with risk, benefit or interest. The use of specific thinkLets is also found to have a moderate positive relationship to individual trust.
\end{abstract}

\section{Introduction}

With the development of information technology, virtual collaboration is developed both in the context of school education and business organization. There are a variety of online collaboration tools so that people can contact others anytime and anywhere. With the forming of a virtual relationship form using the Web [1], connections between individuals are becoming more simple and convenient. Team collaboration without geographic restrictions becomes more efficient.

A large and growing body of literature has investigated trust, especially in the contexts of global virtual teams [2][3][4] and computer-mediated collaboration [5][6][7][8]. For example, Cheng and Macaulay [9] interviewed students in commuter-mediated collaboration and found some new factors and sub-factors of individual trust.

There is a growing body of literature that recognizes the importance of trust in collaboration. While some research have been carried out on the trust development in the context of student group [9][10]. It would also be useful to investigate individual trust development in business virtual teams, as team collaboration in business virtual teams is more and more common and important.

Therefore, in order to answer the question to fill the research gap, this research will review trust, virtual collaboration and individual trust factors over different stages of team collaboration. Moreover, our research will focus on the change of trust factors to explain the development of individual trust. Our research questions are (1) how individual trust develops over time in business virtual teams? (2) what lead to the development of individual trust in business virtual teams?

In the following part of the paper, we will start with a literature review to present the theoretical background in detail. We then proceed with a discussion of our study and analyze results from both quantitative and qualitative perspectives. Then we will conclude our research by analyzing our limitation and implication, and present some ideas for future research.

\section{Theoretical background}

\subsection{Trust}

Trust is a term frequently used in the literature, but to date there is no consensus about its definition. According to Baier [11] and Zand [12], the term trust refers to reliance on others' competency and willingness to look after what is entrusted to their care, not emotional states of affection or warmth. From the perspective of sociology, trust is deemed as a property of collective units, thus trust is applicable to the relations among people, not psychological states [13]. On the contrary, from the perspective of risk tolerance, 
trust is one kind of psychological states which include intention to accept vulnerability based upon positive expectations of another one's intentions or one's behaviors [14].

Four types of trust had been discussed in prior study [45]. The type of 'dispositional trust' is linked to individual traits [15] and is very important at the beginning of a relationship [16][17]. Frequently researched in virtual teams [10], the type of 'interpersonal' trust has three important elements, reliability, predictability, and fairness [18]. Another type of trust is 'situational' trust, which may occur when there is "much to gain from trusting but little attendant risk" [19]. The last type of trust has to do with perceived properties or reliance on system or situation and is called 'System' trust or 'Structural' trust [13].

Trust is of interest because the change of trust reflects the change of psychological states and relations among people. The trust we are going to discuss in this paper is comprehensive. In collaboration, when individuals in the same group build dependability of the partner, gain benefits from collaboration with little risk and collaborate with a credible system, they are more willing to complete the task together.

Trust has a pivotal role in completing team work for individuals to work as members of a team [4][20] [21]. According to Mayer et al. [17], high level of trust is connected with high level of team performance. By providing "internal security" before taking action, trust reduces complexity and is considered to be an essential feature of economy and commerce [22].

\subsection{Virtual collaboration}

As an evolutionary form of network organizations [23], virtual teams are enabled by the development of communication and information technology [24][25].This kind of team is a group of individuals who are geographically dispersed and communicate with the help of technology [26]. As people of a team work together toward the same goal, they must combine their expertise, insights, and resources to complete the group task [27].

There are high flexibility and many other potential benefits for virtual collaboration [25]. Virtual teams often span geographical, temporal, and organizational boundaries [25][28], compared to traditional face-to-face collaboration. Research indicates as well that there may be challenges of virtual team collaboration. As noted by Holton [29], creating opportunities for team members to have the level and depth of dialogue necessary is the challenge faced with team building in a virtual environment. Members of virtual teams interact by social media and professional group collaboration tools instead of facial expression and spoken language. Collaborative processes may be helpful to collaborate in virtual collaboration.

There is a large volume of published studies describing the role of collaborative processes in team collaboration. People can be significantly more productive than those who do not use them with the help of group support systems (GSS) [30]. As an alternative and sustainable way for organizations to derive value from GSS [30], Collaboration Engineering (CE) is an approach to the design of re-usable collaboration processes and technologies, which means practitioners can execute for themselves with designs of collaboration engineering without ongoing support from professional facilitators [27]. Briggs et al. [30] reviewed the literature from the period and concluded several outcomes of CE effort, included Sustained Use, Predictability, Transferability, Reusability, Satisfaction, Commitment and Creativity.

ThinkLets are collaborative activities which are reusable and transferable and cause specific known variations of the general patterns of collaboration, in which people work together toward the same goal [31] [32][33]. ThinkLets can be seen as appropriate ways to package facilitating skills [30]. Each thinkLet encapsulates an expert facilitator's best practice for producing a known pattern in the behaviors of team members who collaborate [33]. ThinkLets can be used and reused as building blocks for team process designs when collaboration is required [27].

\subsection{Trust in virtual collaboration}

More recent attention has focused on trust in team collaboration [6][7][8]. For example, Bos et al. [6] studied the effects of different computer-mediated communication channels on trust development. Trust is indispensable for efficient collaboration and communication which are foundations of amicable and productive relationships in different organizations [34]. According to Deutsch [35], trust involves the notion of motivational relevance and the notion of predictability, which means that expectation leads to behavior.

Research into trust in virtual collaboration has a long history. According to LaForge et al. [36], trust is likely to be particularly important in virtual interaction, because effective collaboration exists only when both parties enter into it with a willingness to open themselves to one another, and cooperate in carrying out a task, solving a problem, and learning. Trust in virtual collaboration may more depend on collaborative tools and collaborative processes, compared with face-to-face collaboration. Without body language and facial expression, people may need more time to know and trust others in virtual 
collaboration.

\subsection{Individual trust factors}

It's important for individuals to trust others when working as part of a virtual team [4][21]. Individual trust and group trust are two main kinds of trust in the research of trust development.

Individual trust is an important type of trust in virtual global team collaboration with the perspective of trust development over time [9]. Individual trust is based on factors that represent the conflicting priorities of the individual in the form of balance, which is also very interesting [37]. The term individual trust we mentioned in this paper refers to the overall trust level individuals felt. We have chosen three main trust factors we think important from previous research findings.

Risk is considered as an individual trust factor, which is associated with providing information to unknown recipients and acting upon information upon received from them [37]. It is considered absolutely necessary in sociological, psychological and economic conceptualizations of trust [38][39][40]. Interdependence and risk are necessary conditions of trust [14], and nature of trust and risk changes as interdependence increases [41]. According to classical exchange theorists, risk offers opportunity for partners to provide their trustworthiness, since trust is more likely to develop when exchange occurs without binding agreements or explicit negotiations [42].

Benefit is considered as all overall perception that involvement will provide individual gain [37]. From economic perspective, trust is a numeration of costs and benefits [39]. Benefit has to do with individual pay. Benefit or gain can be seen as key factors in the development view in situational trust [43]. There is motivation to behave in trustworthy ways and to reap benefits of trusting relationships [44].

Interest indicates an inherent interest in the system and the information available [37]. Individual interest represents traits of attitude, thus evidence from socio-psychological research suggesting positive interactions between trust and interest similarity [45]. In the absence of trust, individual members would not be willing to task risks that others may act in their own self-interest [12].

Risk, benefit and interest play different roles in the development of individual trust. When there is a lack of trust, "people are increasingly unwilling to take risks, demand greater protections against the possibility of betrayal, and increasingly insist on costly sanctioning mechanisms to defend their interests [46]". Then Cheng et al. [47] proposed ideal value to allow small changes to be identified. They argued that the higher the values of benefit and interest, the higher the level of individual trust; the lower the values of benefit and interest, the higher the level of individual trust.

As shown in Figure 1, we can see the relationship between risk and individual trust, the relationship between benefit and individual trust, and the relationship between interest and individual trust.

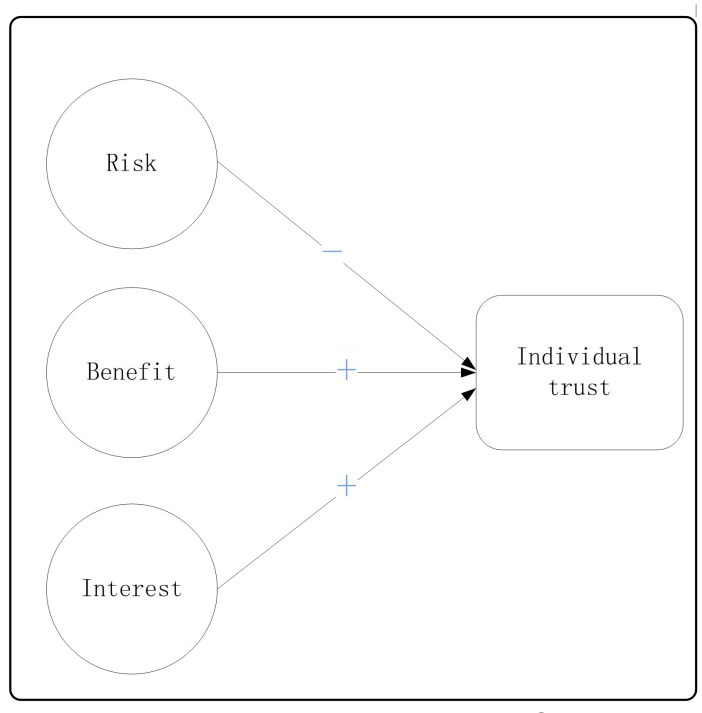

Figure 1.Main individual trust factors

\section{Research design and data collection}

\subsection{Research design}

Researchers used mixed-methods as research methodology. According to Mark and Shotlan [48], mixed-method designs seek convergence of findings by triangulation, seek a range of estimates on the correct answer by bracketing and make complementarity. Researchers adopted questionnaire and semi-structured interview as our main data sources. Researchers often use students of a project team as samples in group decision and collaboration research area [49][50][51][52], while we targeted professional individuals in business teams.

We recruited 70 Chinese professional participants who have work experience to participate in our case to complete certain task during three weeks. In the case, participants were assigned into 8 groups randomly. They didn't know each other in the same group. They were asked to complete a project based on teams. In order to identify team collaboration, all groups were asked to choose a website to find existing problems and provide solutions.

They had little chance and time for team collaboration face to face, since they were busying for their full-time job on weekdays. Under the 
circumstances, they had to complete the project during the weekends with the aid of social media. During their team collaboration, QQ, WeChat, and professional group-chatting software were used without limitation.

Compared with student teams, individuals of business teams showed following features. Firstly, different education background and work environment made team collaboration much more complex. Secondly, they had greater age difference. Thirdly, they didn't have chance to know each other face to face before and after the formation of team as they didn't have to attend class in fixed place.

In addition, we encourage participants to use several useful thinkLets, such as FreeBrainstorm, PopcornSort, FastFocus and StrawPoll.

\subsection{Survey}

The design of the questionnaires was based on the Trust Evaluation Survey of prior study [53] about trust and trust factors in computer mediated collaboration. In our research, we selected all questions of the Trust Evaluation Survey from the perspective of risk, benefit and interest, in addition, we added three questions about individual trust. There were 29 statements in the survey. Questions 1-14 were associated with risk, questions 15-20 were associated with benefits, questions 21-26 were associated with interest, and questions 27-29 were associated with individual trust.

For all the questions, a Likert scale was used. All participants were required to respond to the 29 statements on a scale of 1-5. 1 represents the strongest disagreement and 5 represents the strongest agreement. For example, value 5 for interest is the highest interest. All participants were asked to fill out the survey three times on the Internet respectively at the three stages of team collaboration. The first survey was taken in the beginning, when the team is forming on the first week. The second survey was issued in the middle of team collaboration on the second week. The third survey was taken at the end of the collaboration stage on the third week.

A total of 225 questionnaires were collected. After rejection of 15 invalid questionnaires caused by resubmitting, we collected 210 effective questionnaires altogether, 70 questionnaires each stage.

\subsection{Interview}

Quantitative methods in our research offer an effective way to observe the changing pattern of individual trust and individual trust factors. After three times of survey, interviews were conducted to explore what factors lead to the change of individual trust. Fifteen persons from different groups participated in our semi-structured interview.

We taped and transcribed each interview, which lasted about 15 minutes. Two researchers were at each interview, in which one was in charge of conducting the interview and the other was responsible for taking notes and supplementing interview questions. We are in strict accordance with Eisenhardt's (1989) rules in that we developed detailed interview notes in less than 24 hours, concluded each set of interview notes with the researchers' overall impressions and included all data from each interview [54].

The interview guide had three sections: respondent's background and basic personal information; the change of risk, benefit, interest and individual trust over time and why; and finally, respondent's feedback to the collaboration.

We took several actions to ensure the accuracy of our interview. Firstly, we used free way to conduct interviews, which means interviewees didn't have to answer all questions if they were unwilling. Secondly, we verified the interview by asking the same people similar questions to avoid error of language expressions. Thirdly, we sent interview notes to corresponding interviewees to avoid tiny mistakes.

\section{Data analysis}

We carried on quantitative analysis based on questionnaires we retrieved and qualitative analysis based on data from subjective question of questionnaires and interview.

\subsection{Quantitative analysis}

We conducted quantitative analysis of the 210 effective questionnaires collected by three times. We did general analysis and the change of trust factors over time.

From the questionnaire statistical data, 70 participants are composed of a variety of career, including civil servant, college-graduate village official, bank clerk, engineer, analyst, marketing specialist, state worker, financial staff and so on. The participants are all Chinese working in China. They have work experience from 2 years to more than 10 years. The participants were aged from 24 to 40 years, including males and females.

(1) General analysis

Simple statistical analysis was used to observe whether individual trust has been improved during the team collaboration. We calculated the mean scores of trust of three stages as shown in Table 1.

It can be seen from the data in Table 1 that trust improved over time. Table 1 reveals that there has been 
a growth in individual trust since the first stage. At the first stage, the mean score for trust is 3.91 , which rises to 4.19 on the second stage. What is interesting in this data is that the trust level is 4.47 on the third stage (the highest level is 5 point).

Table 1.Mean scores of individual trust and individual trust factors over time

\begin{tabular}{c|c|c|c}
\hline Stage & 1 & 2 & 3 \\
\hline $\begin{array}{c}\text { Individual } \\
\text { Trust }\end{array}$ & 3.91 & 4.19 & 4.47 \\
\hline Risk & 2.36 & 2.11 & 1.82 \\
\hline Benefit & 4.05 & 4.24 & 4.49 \\
\hline Interest & 4.10 & 4.27 & 4.28 \\
\hline
\end{tabular}

(2)The changing patterns of individual trust factors

Next, we computed mean scores of trust factors in the following analysis over three stages (see Table 1 and Figure 2). For the changing pattern of risk, we found that it decreased from the first stage to the third stage. For the changing patterns of benefit and interest, we found that they both decreased from the first stage to the third stage.

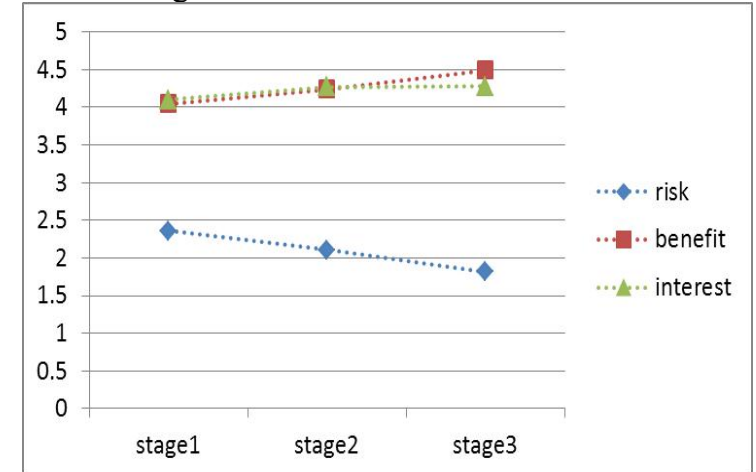

Figure 2.Changing patterns of individual trust factors over time

To further validate the changing pattern as shown in Table 1 and Figure 2, we conducted Paired Samples tTest for the trust factors over time to observe whether there is significant change between two successive stages.

As shown in Table 2, we list the change of each trust factor and corresponding significance level.

Table 2.Paired samples t-test for the individual trust factors over time

\begin{tabular}{|c|c|c|}
\hline \multirow{2}{*}{ Individual Trust Factors } & \multicolumn{2}{|c|}{ Stage } \\
\hline & Stage $1 \rightarrow$ Stage 2 & Stage2 $\rightarrow$ Stage3 \\
\hline Risk & $3.25 * *$ & $3.44 * *$ \\
\hline Benefit & $-2.06^{*}$ & $-2.56^{*}$ \\
\hline Interest & $-1.86^{+}$ & $-2.44 *$ \\
\hline
\end{tabular}

Significance level: $+\mathrm{p}<0.1 ;{ }^{*} \mathrm{p}<0.05 ;{ }^{* *} \mathrm{p}<0.01$

It can be seen from the data in Table 2 that three trust factors changed in different significant level between two successive stages. For the change of risk, significant reduction $(\mathrm{p}<0.01)$ was found compared with the first stage. For the change of benefit, there were significant increases $(p<0.05)$ from the first stage to the second stage and from the second stage to the third stage. For the change of interest, a significant increase $(p<0.1)$ from the first stage to the second stage and a significant increase $(\mathrm{p}<0.01)$ from the second stage to the third stage were recorded.

\subsection{Qualitative analysis}

To support the quantitative data received and analyzed from the questionnaire and explore new factors of individual trust in virtual team collaboration, we also conducted qualitative analysis, included a number of questions to be answered qualitatively by the participants, which were further analyzed. Open-ended questions included in the last part of the questionnaire along with the semi-structured interview are served as data for our qualitative analysis.

We coded simple quotations according to interviewees and content related. The numbers from 1 to 15 represent the first to the fifteenth interviewees. For example, interview ID I1 means the quotations from the first interviewee.

(1) The development of trust

For the change of trust, we conclude from the comments below that trust had been improved over time, which verifies the results of quantitative analysis. A variety of perspectives were expressed to demonstrate the importance of trust improvement for team collaboration. A common view amongst interviewees was that time and communication are 
important during the forming of trust. As the team members were more familiar with each other, team would benefit from the process of information sharing. I1: I can feel the improvement of trust from the first week to the second week, but not so obvious. We were not so familiar.

13: We trust each other more and more. It's helpful for us to complete the team project by minimizing meeting time and reaching agreement faster.

17: Trust had been improved since we form the team. It is great for us to share information with other team members.

(2) The change of risk

For the change of risk, a common view amongst interviewees was that risk was decreased over time, which verified the results of quantitative analysis. Further analysis showed that some teams were facing with conflict of option mainly. Conflict of option can be seen as one source of risk. When there is conflict of option, the relationship may be damaged, especially in the initial stages of collaboration.

Interestingly, it was also suggested that the use of particular thinkLets had a moderate positive relationship to less conflict of option. The use of StrawPoll helped to reduce the conflict of option and improve efficiency.

In this case, a good collaboration process could make it easier to collaborate. What's more, expressing concern for others was important to team building and team collaboration.

I2: We often had conflict of option, so it's difficult to reach agreement at the beginning of our collaboration. I5: We solved the problem (conflict of option) with thinkLets by its function of voting (StrawPoll). According to the usual practice of StrawPoll, the minority is subject to the majority.

I11: Our biggest risk is that we didn't have united time, so we had little opportunities to discuss together.

I12: We voted with a thinkLet, which was helpful to make decision.

(3) The change of benefit

For the change of benefit, the comment below illustrates that individuals had gained more and more benefit over time, which verified the results of quantitative analysis. Further analysis showed that individuals benefited from two aspects, included interpersonal communication and information sharing. A possible explanation for this might be that we trust others not only for its ability related with work, but also in others' personal skills.

Interestingly, when the participants were asked if there existed something else to help gain benefit, majority commented that thinkLets were correlated with higher individual benefit by promoting information sharing. The use of FreeBrainstorm helped participants to share more information in the team collaboration.

I1: I have gained benefit about E-business over time by information sharing.

I12: I have learned a lot from other team members by the process of brainstorming. I made friends with my team members and would ask for some skills.

I15: I realized something by this chance of team work. One of the most important is that you should learn to listen to opinions and thoughts of others.

(4) The change of interest

For the change of interest, we concluded from the comments below that interest had been increased over time, which verified the results of quantitative analysis. Most participants indicated that they were interested with their team projects. There were some suggestions that team working is one source of their interest.

I4: I'm interested in our project, as we selected the subject together.

I6: I like team working. It's interesting to work together with others.

113: The project of our team was average for me initially, but later I liked the project more and more.

\section{Discussion and conclusions}

\subsection{Discussion}

As mentioned in the literature review, individual trust is important for team collaboration [6][7][8], particularly in virtual interaction. The current study found that individual trust had been improved over time. Another important finding was that trust factors changed in different patterns. The most interesting finding was that we found some reasons why individual trust changed.

With respect to the first research question, it was found that individual trust in business virtual teams had been improved from the first stage to the third stage. We concluded the individual trust improvement from quantitative analysis and verified the result from qualitative analysis.

During the development of trust, three factors changed in different patterns as we have observed. Risk decreased from the first stage to the third stage, while benefit and interest increased over time, which verified ideal value [47] of individual trust factors also exists in the context of business virtual teams.

With respect to the second research question, we conclude a framework of individual trust in business virtual teams, as shown in Figure 3. It was found that conflict of option, interpersonal communication, information sharing, thinkLets and team working are associated with the change of individual trust and three 
main trust factors, risk, benefit and interest.

Moreover, among all these factors, conflict of option are found to have a relationship with risk, information sharing and interpersonal communication are found to have an association with benefit and team working is found to be related with interest. In the context of individual trust in computer mediated group collaboration, Cheng and Macaulay [9] had found conflict of option as one sub-factor of risk and team working as one sub-factor of interest.

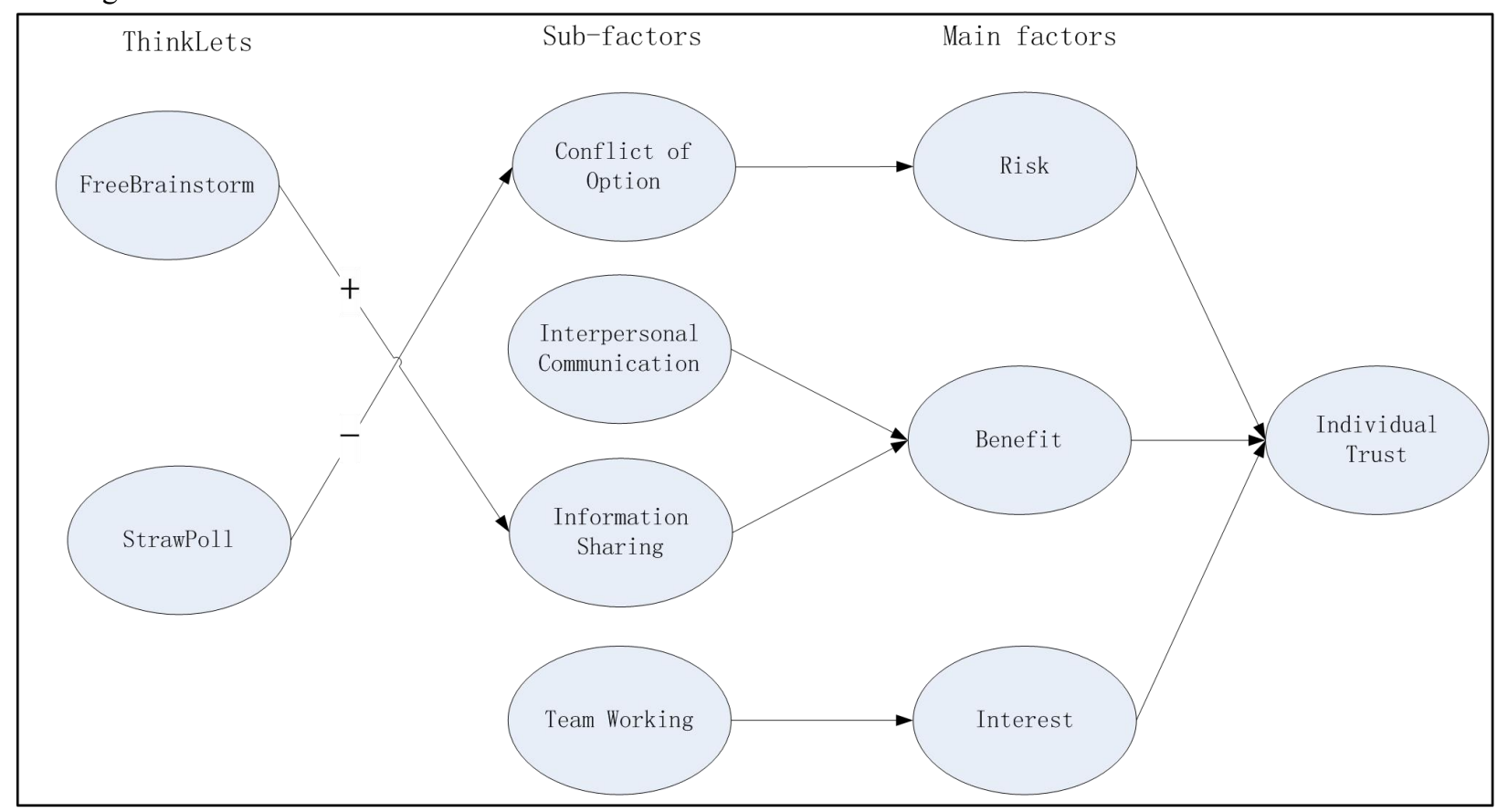

Figure 3.A framework of individual trust in business virtual teams

\subsection{Conclusions and future research}

This study set out to determine the development of individual trust and why individual trust changes over time in business virtual teams. We have answered two research questions mentioned before using quantitative analysis and qualitative analysis.

The present study makes several noteworthy contributions to research individual trust development in business virtual teams. Firstly, ideal values of risk, benefit and interest are verified to exist in business virtual teams, which were proposed in the context of student group [47]. Secondly, we have found some factors associated with the individual trust development by changing levels of risk, benefit and interest. These findings enhance our understanding of individual trust development in the process of virtual team collaboration. Thirdly, this research provides a framework for the exploration of relation between the use of specific thinkLets and trust in virtual collaboration, compared with research
The research has also shown that the use of specific thinkLets has a strong positive association with higher individual trust in business virtual teams and is considered to play important roles in the development of trust. Firstly, the use of specific thinkLets is found to be related with low risk by settling conflict of option. Secondly, we find that the use of thinkLets is correlated with high benefit by improving information sharing. 
Further investigation and experimentation into individual trust in business virtual team is strongly recommended. More research is needed to better understand the development of individual trust. Moreover, it is suggested that the association of trust factors is investigated in future studies. In addition, it would be interesting to explore the relationship between collaborative processed or collaborative tools and trust in team collaboration.

\section{Acknowledgement}

The authors would like to thank the National Natural Science Foundation of China (Grant No.71571045) for providing funding for part of this research.

\section{References}

[1]A. Azadegan, and G.L. Kolfschoten, "An Assessment Framework for Practicing Facilitator", Group Decision and Negotiation, 23(5), 2014, pp. 1013-1045.

[2]S.L. Jarvenpaa, K. Knoll, and D.E. Leidner, "Is Anybody out there? Antecedents of Trust in Global Virtual Teams", Journal of Management Information Systems, 14(4), 1998, pp. 29-64.

[3]S. Sarker, M. Ahuja, S. Sarker, and S. Kirkeby, "The Role of Communication and Trust in Global Virtual Teams: A Social Network Perspective", Journal of Management Information Systems, 28(1), 2011, pp. 273-310.

[4]S.L. Jarvenpaa, T.R. Shaw, and D.S. Staples, "Toward Contextualized Theories of Trust: The Role of Trust in Global Virtual Teams", Information Systems Research, 15(3), 2004, pp. 250-267.

[5]J.M. Wilson, S.G. Straus, and B. McEvily, "All in Due Time: The Development of Trust in Computer-mediated and Face-to-face Teams", Organizational Behavior and Human Decision Processes, 99(1), 2006, pp. 16-33.

[6]N. Bos, J. Olson, D. Gergle, G. Olson, and Z. Wright, "Effects of Four Computer-mediated Communications Channels on Trust Development", ACM Conference on Human Factors and Computing Systems, New York, 2002.

[7]N.S. Hill, K.M. Bartol, P.E. Tesluk, and G.A. Langa, "Organizational Context and Face-to-face Interaction: Influences on the Development of Trust and Collaborative Behaviors in Computer-mediated Groups", Organizational Behavior and Human Decision Processes, 108(2), 2009, pp. 187-201.

[8]J. Riegelsberger, M.A. Sasse, and J.D. McCarthy, "The Researcher's Dilemma: Evaluating Trust in Computer-mediated Communication", International Journal of Human-Computer Studies, 58(6), 2003, pp. 759-781.

[9]X. Cheng, and L. Macaulay, "Exploring Individual Trust Factors in Computer Mediated Group Collaboration: A Case Study Approach", Group Decision and Negotiation, 23(3), 2014, pp. 533-560.

[10]X. Cheng, S. Fu, J. Sun, Y. Han, J. Shen, and A. Zarifis, "Investigating Individual Trust in Semi-virtual
Collaboration of Multicultural and Unicultural Teams", Computers in Human Behavior, 62, 2016, pp. 267-276.

[11]A. Baier, "Trust and Antitrust", Ethics, 96(2), 1986, pp. 231-260.

[12]D.E. Zand, "Trust and Managerial Problem Solving", Administrative Science Quarterly, 17(2), 1972, pp. 229-239.

[13]J.D. Lewis, and A. Weigert, "Trust as A Social Reality", Social Forces, 63(4), 1985, pp. 967-985.

[14]D.M. Rousseau, S.B. Sitkin, R.S. Burt, and C. Camerer, "Not so Different after all: A Cross-discipline View of Trust", Academy of Management Review, 23(3), 1998, pp. 393-404.

[15]E.H. Erikson, Childhood and Society, New York, Norton, 1963.

[16]D.H. McKnight, C.J. Kacmar, and V. Choudhury, "Dispositional Trust and Distrust Distinctions in Predicting High-and Low-risk Internet Expert Advice Site Perceptions", E-Service, 3(2), 2004, pp. 35-58.

[17]R.C. Mayer, J.H. Davis, and F.D. Schoorman, "An Integrative Model of Organizational Trust", Academy of Management Review, 20(3), 1995, pp. 709-734.

[18]A. Zaheer, B. McEvily, and V. Perrone, "Does Trust Matter? Exploring the Effects of Interorganizational and Interpersonal Trust on Performance", Organization Science, 9(2), 1998, pp. 141-159.

[19]H.W. Kee, and R.E. Knox, "Conceptual and Methodological Considerations in the Study of Trust and Suspicion", Journal of Conflict Resolution, 14(3), 1970, pp. 357-366.

[20]X. Cheng, Y. Li, J. Sun, and J. Huang, “Application of A Novel Collaboration Engineering Method for Learning Design: A Case Study", British Journal of Educational Technology, 47(4), 2016, pp. 803-818.

[21]A.C. Costa, "Work Team Trust and Effectiveness", Personnel Review, 32(5), 2003, pp. 605-622.

[22]A. Abdul-Rahman, and S. Hailes, "Supporting Trust in Virtual Communities", Proceedings of the 33rd Hawaii International Conference on System Science, Maui, Hawaii, 2000.

[23]R.E. Miles, and C.C. Snow, "Organizations: New Concepts for New Forms", California Management Review, 28(3), 1986, pp. 62-73.

[24]H.G. Brown, M.S. Poole, and T.L. Rodgers, "Interpersonal Traits, Complementarity, and Trust in Virtual Collaboration", Journal of Management Information Systems, 20(4), 2004, pp. 115-138.

[25]S.L. Jarvenpaa, and D.E. Leidner, "Communication and Trust in Global Virtual Teams", Organization Science, 10(6), 1999, pp. 791-815.

[26]B.S. Bell, and S.W.J. Kozlowski, "A Typology of Virtual Teams Implications for Effective Leadership", Group \& Organization Management, 27(1), 2002, pp. 14-49.

[27]G.J. De Vreede, and R.O. Briggs, "Collaboration Engineering: Designing Repeatable Processes for High-value Collaborative Tasks", Proceedings of the 38th Hawaii International Conference on System Science, Maui, Hawaii, 2005.

[28]K.M. Chudoba, E. Wynn, M. Lu, and M.B. Watson-Manheim, "How Virtual Are We? Measuring 
Virtuality and Understanding Its Impact in A Global Organization", Information Systems Journal, 15(4), 2005, pp. 279-306.

[29]J.A. Holton, "Building Trust and Collaboration in A Virtual Team", Team Performance Management: An International Journal, 7(3/4), 2001, pp. 36-47.

[30]R.O. Briggs, G.J. De Vreede, and J.F. Nunamaker Jr, "Collaboration Engineering with ThinkLets to Pursue Sustained Success with Group Support Systems", Journal of Management Information Systems, 19(4), 2003, pp. 31-64.

[31]R.O. Briggs, G.J. De Vreede, J.F. Nunamaker Jr, and D. Tobey, "ThinkLets: Achieving Predictable, Repeatable Patterns of Group Interaction with Group Support Systems (GSS)", Proceedings of the 34th Hawaii International Conference on System Science, Maui, Hawaii, 2001.

[32]G.L. Kolfschoten, R.O. Briggs, G.J. De Vreede, P. H. Jacobs, and J.H. Appelman, "A Conceptual Foundation of the ThinkLet Concept for Collaboration Engineering", International Journal of Human-Computer Studies, 64(7), 2006, pp. 611-621.

[33]G.J. De Vreede, R.O. Briggs, and G.L. Kolfschoten, "ThinkLets: A Pattern Language for Facilitated and Practitioner-guided Collaboration Processes", International Journal of Computer Applications in Technology, 25(2/3), 2006, pp. 140-154.

[34]M. Tschannen-Moran, and W.K. Hoy, "A Multidisciplinary Analysis of the Nature, Meaning, and Measurement of Trust", Review of Educational Research, 70(4), 2000, pp. 547-593.

[35]M. Deutsch, "Trust and Suspicion”, Journal of Conflict Resolution, 2, 1958, pp. 265-279.

[36]T. LaForge, F. Leary, H. Naboisek, H.S. Coffey, and M.B. Freedman, "The Interpersonal Dimension of Personality: II. An Objective Study of Repression”, Journal of Personality, 23(2), 1954, pp. 129-153.

[37]T. Nolan, R. Brizland, and L. Macaulay, "Individual Trust and Development of Online Business Communities", Information Technology \& People, 20(1), 2007, pp. 53-71.

[38]J.B. Rotter, "A New Scale for the Measurement of Interpersonal Trust”, Journal of Personality, 35(4), 1967, pp. 651-665.

[39]J.S. Coleman, Foundations of Social Theory, Harvard University Press, Cambridge, MA, 1994.

[40]O.E. Williamson, "Calculativeness, Trust, and Economic organization", The Journal of Law \& Economics, 36(1), 1993, pp. 453-486.

[41]D.L. Shapiro, B.H. Sheppard, and L. Cheraskin, "Business on A Handshake", Negotiation Journal, 8(4), 1992, pp. 365-377.

[42]L.D. Molm, N. Takahashi, and G. Peterson, "Risk and Trust in Social Exchange: An Experimental Test of A Classical Proposition", American Journal of Sociology, 105(5), 2000, pp. 1396-1427.

[43]R. Lewick, and B. Bunker, Developing and Maintaining Trust in Work Relationships, In R.M. Kramer \& T.R. Tyler (Eds.) Trust in Organizations: Frontiers of Theory and Research, Sage Publications, London, 1996.

[44]R.D. Putnam, "The Prosperous Community", The American Prospect, 4(13), 1993, pp. 35-42.

[45]X. Cheng, G. Yin, A. Azadegan, and G.L Kolfschoten,
"Trust Evolvement in Hybrid Team Collaboration: A Longitudinal Case Study", Group Decision and Negotiation, 25(2), 2016, pp. 267-288.

[46]R.M. Kramer and T.R. Tyler, "Whither Trust", In R.M. Kramer \& T.R. Tyler (Eds.), Trust in Organizations: Frontiers of Theory and Research, Sage Publications, London, 1996.

[47]X. Cheng, L. Macaulay, and A. Zarifis, "Modeling Individual Trust Development in Computer Mediated Collaboration: A Comparison of Approaches", Computers in Human Behavior, 29(4), 2013, pp.1733-1741.

[48]M.M. Mark, and R.L. Shotland, "Alternative Models for the Use of Multiple Methods", New Directions for Program Evaluation, 1987(35), 1987, pp. 95-100.

[49]C. Gipps, "Developments in Educational Assessment: What Makes A Good Test?" Assessment in Education, 1(3), 1994, pp. 283-292.

[50]R.C.W. Kwok, and J. Ma, "Use of A Group Support System for Collaborative Assessment", Computers \& Education, 32(2), 1999, pp. 109-125.

[51]D. Richards, "Designing Project-based Courses with A Focus on Group Formation and Assessment", ACM Transactions on Computing Education, 9(1), 2009, pp.2-40. [52]C.H. Chiu, H.Y. Yang, T.H. Liang, and H.P. Chen, "Elementary Students' Participation Style in Synchronous Online Communication and Collaboration", Behaviour \& Information Technology, 29(6), 2010, pp. 571-586.

[53]X. Cheng, T. Nolan, and L. Macaulay, "Don't Give up the Community: A Viewpoint of Trust Development in Online Collaboration", Information Technology \& People, 26(3), 2013, pp. 298-318.

[54]K.M. Eisenhardt, "Building Theories from Case Study Research", Academy of Management Review, 14(4), 1989, pp. 532-550.

\section{Appendix 1: Survey}

This survey aims to evaluate the development of individual trust in teams. Please choose value scale from 1 to $5,1=$ strongly disagree, $3=$ neutral, $5=$ strongly agree.

Part 1:

1. I am unhappy to provide information to other team members.

2. I am unhappy to receive and act upon information from other team members.

3. The physical environment has limited the ability of the team to collaborate.

4. Resource problems have limited the ability of the team to collaborate.

5. The lack of background knowledge of others has limited the team performance.

6. The lack of skills of others has limited team performance.

7. Team members have different perceptions of the problem being investigated. 
8. Different perceptions of the problems have limited team effectiveness.

9. Some team members are unwilling to compromise. 10. There isn't a good team spirit in my team.

11. I don't like the anonymity feature.

12. Anonymity caused some problems in collaboration within my team.

13. I feel that some team members want to dominate the group.

14. I found it difficult to make a contribution to the team.

Part 2:

15. I am satisfied with being involved in my team.

16. I share the same objectives with others in my team.

17. I share mutual benefits with others in my team.

18. I have gained some networking benefits from the team collaboration.

19. I have gained some personal benefits from the team collaboration.

20. I have gained benefits which can be used for future projects.

Part 3:

21. I am interested in collaborating with others in my team.

22. I have an interest in the information shared with other team members.

23. I have an interest in the contribution made by other team members.

24. I share social interests with members of my team.

25. I have an interest in the topics of my team collaboration.

26. I want to continue working with my team in the future.

Part 4:

27. In general, what do you think about individual trust in your team?

28 . I trust my team very much.

29. All my team members trust me very much. 